\title{
Health risks for marine mammal workers
}

\author{
Tania D. Hunt ${ }^{1}$, Michael H. Ziccardii ${ }^{1}$, Frances M. D. Gulland ${ }^{2}$, Pamela K. Yochem ${ }^{3}$, \\ David W. Hird ${ }^{1,4}$, Teresa Rowles ${ }^{5}$, Jonna A. K. Mazet ${ }^{1,4, *}$ \\ ${ }^{1}$ Wildlife Health Center, School of Veterinary Medicine, and ${ }^{4}$ Department of Medicine and Epidemiology, \\ University of California, One Shields Avenue, Davis, California 95616, USA \\ ${ }^{2}$ The Marine Mammal Center, Golden Gate National Recreation Area, Sausalito, California 94965, USA \\ ${ }^{3}$ Hubbs-SeaWorld Research Institute, 2595 Ingraham Street, San Diego, California 92109, USA \\ ${ }^{5}$ National Marine Fisheries Service, Office of Protected Resources (F/PR2), East-West Highway, Silver Spring, \\ Maryland 20910, USA
}

\begin{abstract}
Marine mammals can be infected with zoonotic pathogens and show clinical signs of disease, or be asymptomatic carriers of such disease agents. While isolated cases of human disease from contact with marine mammals have been reported, no evaluation of the risks associated with marine mammal work has been attempted. Therefore, we designed a survey to estimate the risk of work-related injuries and illnesses in marine mammal workers and volunteers. The 17 -question survey asked respondents to describe their contact with marine mammals, injuries sustained, and/or illnesses acquired during their period of marine mammal exposure. Most respondents, $88 \%$ (423/483), were researchers and rehabilitators. Of all respondents, $50 \%$ (243/483) reported suffering an injury caused by a marine mammal, and $23 \%(110 / 483)$ reported having a skin rash or reaction. Marine mammal work-related illnesses commonly reported included: 'seal finger' (Mycoplasma spp. or Erysipelothrix rhusiopathiae), conjunctivitis, viral dermatitis, bacterial dermatitis, and non-specific contact dermatitis. Although specific diagnoses could not be confirmed by a physician through this study, severe illnesses were reported and included tuberculosis, leptospirosis, brucellosis, and serious sequelae to seal finger. Risk factors associated with increased odds of injury and illness included prolonged and frequent exposure to marine mammals; direct contact with live marine mammals; and contact with tissue, blood, and excretions. Diagnosis of zoonotic disease was often aided by veterinarians; therefore, workers at risk should be encouraged to consult with a marine mammal veterinarian as well as a physician, especially if obtaining a definitive diagnosis for an illness becomes problematic.
\end{abstract}

KEY WORDS: Marine mammal $\cdot$ Disease $\cdot$ Zoonoses $\cdot$ Occupational hazards $\cdot$ Seal finger Resale or republication not permitted without written consent of the publisher

\section{INTRODUCTION}

Despite the fact that marine mammals can become sick due to infection with, or be healthy carriers of, viral, bacterial, fungal, and protozoal zoonotic pathogens (disease agents transmissible between animals and humans), the risk of acquiring disease by scientists, wildlife rehabilitators, and animal trainers handling marine mammals is not well understood (Buck \& Schroeder 1990, Geraci \& Ridgway 1991, Cowan et al. 2001). An example of a commonly seen marine mammal zoonotic disease includes 'seal finger,' a common skin infection reported in whalers and sealers caused by a mycoplasmal organism carried in the mouth and on the skin of marine mammals (Baker et al. 1998, Hartley \& Pitcher 2002). Epidemics of food-borne illnesses, such as salmonellosis, trichinellosis, and toxoplasmosis, have also been reported in the native peoples of Arctic and Australasian regions who harvest marine mammals as part of a traditional diet (Cawthorn 1997, Tryland 2000). For example, botulism Type E, characterized by symmetric flaccid paralysis, was reported in western Alaska in people who had eaten a beached whale (McLaughlin et al. 2004). 
Zoonotic disease transmission as a result of occupational contact between marine mammals and humans has been reported, and these include infections of marine mammals with zoonotic agents, such as Staphylococcus aureus and Vibrio parahemolyticus (Palmer et al. 1991, Cowan et al. 2001), as well as gastritis and localized skin infections in attending veterinarians (P. Schroeder pers. comm.). Although hundreds of seal finger or seal finger-like cases have been reported in fishermen and sealers, only 8 cases in scientists or rehabilitators have been described in the scientific literature (Rodahl 1953, Markham \& Polk 1979, Sargent 1980, Eadie et al. 1990, Cawthorn 1994, Baker et al. 1998, Hartley \& Pitcher 2002). Cases of seal finger-like diseases in fishermen are more likely to be caused by Erysipelothrix rhusiopathiae acquired from fish (thereby more aptly named 'fish-handlers disease'), whereas cases acquired from marine mammals are presumably mostly caused by Mycoplasma spp. (Robson et al. 1998, Cowan et al. 2001). Other reports of marine mammal workers acquiring skin diseases include: 1 case of Mycobacterium marinum from a bottlenose dolphin Tursiops truncatus (Flowers 1970); 4 cases of Erysipelothrix rhusiopathiae from a beached pilot whale Globicephala melaena (Chastel et al. 1975); 1 case of a calicivirus, San Miguel sea lion virus, from northern fur seals Callorhinus ursinus (Smith et al. 1998); and 3 cases of sealpox from grey seals Halichoerus grypus (Hicks \& Worthy 1987, Clark et al. 2005). Infections with $M$. marinum and E. rhusiopathiae caused painful dermal abscesses at the site of contamination, while the viral infections (sealpox and San Miguel sea lion virus) resulted in edematous nodules or vesicles.

In addition to skin infections, generalized zoonotic infections have been observed in marine mammal workers. One case of Blastomyces dermatitidis acquired from a bottlenose dolphin has been reported; a veterinarian treating the affected animal experienced a pustular dermatitis with lymphangitis and lymphadenitis (Cates et al. 1986). Similarly, transmission of Mycobacterium bovis from a New Zealand fur seal Arctocephalus forsteri to an oceanarium worker has been documented (Thompson et al. 1993), with the seal trainer experiencing a tuberculous pneumonia and severe airway obstruction. Lobo's disease (keloidal blastomycosis), caused by the fungus Lacazia loboi (formerly Loboa loboi), has also been transmitted from a captive bottlenose dolphin to a handler (Symmers 1983). Three researchers acquired leptospirosis from California sea lion Zalophus californianus carcasses and experienced acute nephritis and clinical signs consistent with acute renal failure (Baker et al. 1998). One laboratory worker developed brucellosis after handling tissues from an infected seal (Brew et al. 1999).
Finally, 4 aquarium workers suffered severe purulent conjunctivitis caused by influenza A virus acquired from harbor seals Phoca vitulina (Webster et al. 1981).

These case reports document the potential for organisms in marine mammals to infect humans. However, they do not provide information on risk factors associated with humans acquiring such infections. Animal trainers, veterinarians, and volunteers who staff wildlife rehabilitation centers treating sick and injured marine mammals, as well as field researchers and workers at aquaria and oceanaria that exhibit marine mammals to the public, are likely to be at risk. During certain recreational activities, the public may also be at risk of transmitting diseases to and contracting diseases from marine mammals. Thousands of people visit oceanaria where contact with marine mammals (or the water in which they swim) is common. Many also participate in 'swim-with-the-dolphin' programs. In 1989, over 8000 people participated in these 'swim-with' programs in the USA alone (National Marine Fisheries Service 1990). While information on the injurious attacks made by dolphins on humans is available, less attention has been paid to the potential for transmission of infectious diseases (exceptions include Johnston \& Fung 1969, Myers 1970, Streitfeld \& Chapman 1976, Polley 2005). In addition, the interaction between diseased marine mammals and humans in these occupational contexts may increase the flow of pathogens between marine mammals and humans and contribute to the emergence of infectious disease.

The purpose of this study was to evaluate the risk of human injury and illness associated with marine mammal rehabilitation, captive management, and research activities by surveying a sample of people involved in these activities. While the results help to identify risk factors for marine mammal workers, the survey instrument was designed to protect the anonymity of the respondents; therefore, all injuries and illness were self-reported, and corroboration of specific diagnoses by physicians was not possible.

\section{MATERIALS AND METHODS}

Survey administration and participants. A 17-item questionnaire (Appendix 1) was formulated to evaluate risk of injury and illness associated with occupational contact with marine mammal species. After piloting the questionnaire with a small group of marine mammal workers and obtaining reviews by experts in the field, it was made available via the internet to over 5000 potential responders from 72 countries. Participants were sought primarily by email notices posted on the MARMAM listserv. $\stackrel{\mathbf{1}}{\mathrm{A}}$ paperbased version of the same questionnaire was also 
made available to participants at both the Biennial Conference on the Biology of Marine Mammals (November 28 to December 3, 2001, Vancouver, British Columbia, Canada) and the International Association for Aquatic Animal Medicine (May 4 to 8, 2002, Albufeira, Portugal), as well as to individuals upon request. Postcards containing the questionnaire's web address were also provided at the conferences. Respondents participated in the survey in complete anonymity. Responses originating from the web-based questionnaire were collected electronically; the paper-based responses were received by mail at the Wildlife Health Center, University of California, Davis, California, USA.

Questionnaire content. The 17 questions (Appendix 1) allowed for evaluation of the respondents' interactions with marine mammals and the description of injuries and illnesses suffered by respondents during the time in which they were exposed to marine mammals. Questions regarding respondents' association with marine mammals addressed the primary nature of occupational contact (research, rehabilitation, zoo and aquaria employment, and 'swim-withthe-dolphin' programs), the duration and frequency of contact, the type of marine mammal-specific occupational training received, and specific modes of contact (direct contact with live marine mammals while out of water or while in the water with them, contact with water in which a marine mammal swam, contact with marine mammal excretions and/or vomitus, contact with tissue or blood samples from marine mammals, cleaning or repairing enclosures or equipment used in the care of marine mammals, and contact with dead marine mammals). Participants could select only one primary type of occupational contact but were allowed to indicate more than one type of training and specific modes of contact. Questions regarding respondents' injuries and illnesses were designed to explore the nature and duration of the injuries and associations with marine mammal contact. Note that injuries and illnesses were attributed by the respondents to their marine mammal contact; confirmation of each diagnosis by a physician was not possible using only the survey instrument. Additional questions concerned the demographics and health of the respondents and allowed respondents to describe any specific diagnoses and treatments received for their reported illnesses and injuries, including the success of those treatments.

${ }^{1}$ MARMAM is an edited e-mail discussion list which focuses on marine mammal research and conservation, run through the University of Victoria; publishers: Robin Baird \& Megan Ferguson (marmamed@uvic.ca); http://whitelab.biology.dal. $\mathrm{ca} / \mathrm{marmam} . \mathrm{htm}$
Data analysis. The prevalence of 4 health outcomes (trauma, skin rash/reaction, respiratory illness, and prolonged malaise) were calculated from the total number of respondents. The outcomes were further examined for severity and occurrence subsequent to or as a result of marine mammal contact.

Logistic regression was used to evaluate potential risk factors associated with the 4 outcomes using the backward stepwise likelihood ratio method (Daniel 1999). Odds ratios and $95 \%$ confidence intervals (CIs) were calculated in order to assess the magnitude of associations (SPSS, v. 11.0.1). Where appropriate, interaction terms among contact types, and duration and frequency of contact were included in the model.

\section{RESULTS}

\section{Survey response and respondent characteristics}

A total of 483 responses were received (45\% male and $55 \%$ female respondents), 413 of which were collected via the internet. Respondents most frequently reported research as their primary type of occupational marine mammal contact ( $\mathrm{n}=283$ ) (Fig. 1). Nearly $80 \%$ (386) of respondents reported receiving training in animal restraint and handling, 76\% in tissue and blood sampling, $44 \%$ in infectious disease prevention protocols, and $49 \%$ in occupational safety. Most respondents (392) had substantial exposure to marine mammals with $>5 \mathrm{yr}$ of experience and/or $>50 \mathrm{~d} \mathrm{yr}^{-1}$ of contact (Figs. $2 \& 3$ ).

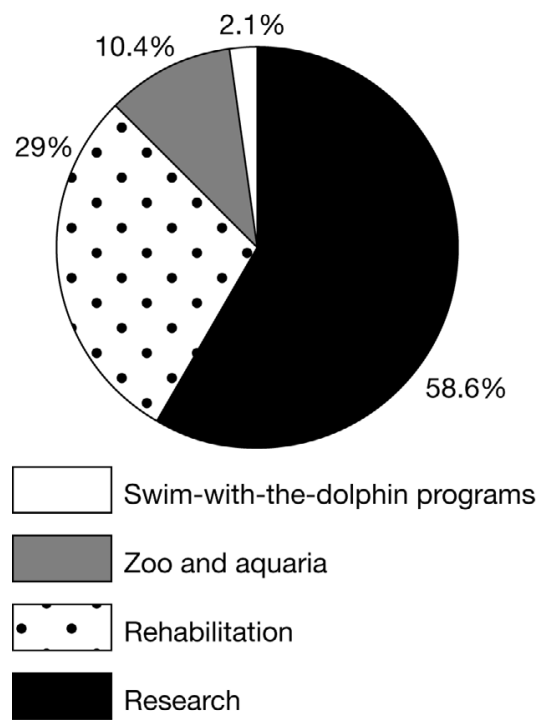

Fig. 1. Primary type of marine mammal contact reported by marine mammal workers $(n=483)$ 


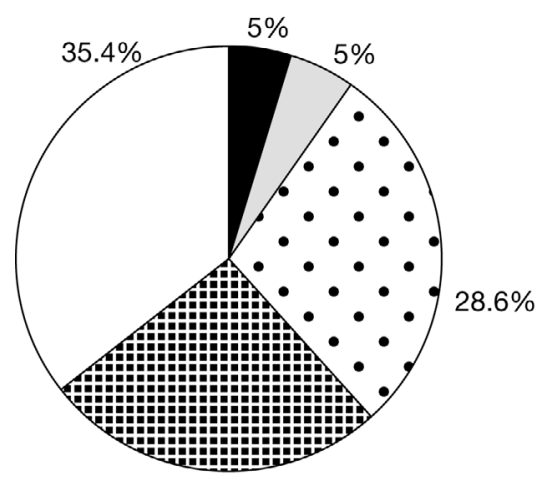

$26.1 \%$

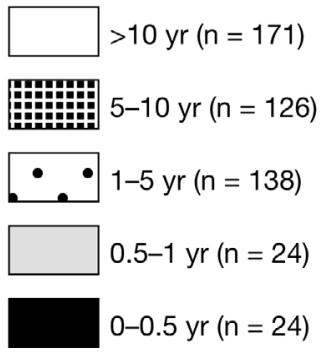

Fig. 2. Duration (yr) of marine mammal contact reported by marine mammal workers $(n=483)$

Of all 483 respondents, $64 \%$ (308) reported having had an injury or illness during the time they were in contact with marine mammals and $54 \%$ (261) believed they had contracted an illness or injury as a direct result of marine mammal contact. Types of injuries and illnesses are shown in Table 1.

\section{Trauma}

A total of 251 (52\%) respondents suffered a traumatic injury as a result of working with marine mammals. Injuries were primarily located on the extremities ( $\mathrm{n}=218 ; 89 \%$ ) but were also incurred on the torso or abdomen $(20 ; 8 \%)$ and on the face $(11 ; 4 \%)$. Ninety $(36 \%)$ of those reporting trauma suffered 1 or more severe injuries, including: a deep wound (77), a deep wound requiring stitches (26), or a fractured bone (10). Other severe injuries described included a dislocated shoulder and an amputation. Also, 38 (15\%) reported having been bitten. Of the total number of reported injuries, 5 were self-inflicted traumas, including needle sticks and necropsy knife cuts.

The results of a multivariate logistic regression analysis showed that statistically significant risk factors $(p<0.05)$ associated with traumatic injuries included marine mammal contact duration of $>5 \mathrm{yr}$; contact frequency of $>50 \mathrm{~d} \mathrm{yr}^{-1}$; and having contact specifically with live animals, excretions and/or vomi-

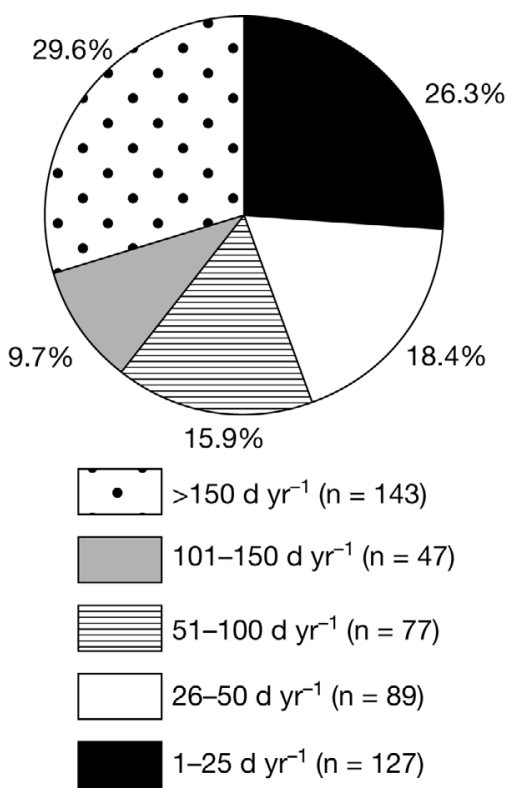

Fig. 3. Frequency $\left(\mathrm{d} \mathrm{yr}^{-1}\right)$ of marine mammal contact reported by marine mammal workers $(n=483)$

Table 1. Self-reported health problems attributed to marine mammal contact by marine mammal workers ( $\mathrm{n}=483$ ). Number of commonly reported health problems are detailed in sub-categories

\begin{tabular}{|c|c|}
\hline Health problem & Total \\
\hline Trauma & 251 \\
\hline Deep wounds & 77 \\
\hline Bites & 38 \\
\hline Wounds requiring stitches & 26 \\
\hline Fractures & 10 \\
\hline Skin reactions & 72 \\
\hline Erysipelothrix rhusiopathae ${ }^{\mathrm{a}}$ & 4 \\
\hline Erysipeloid infections $^{b}$ & 3 \\
\hline Mycoplasma spp. ${ }^{\mathrm{b}}$ & 2 \\
\hline Other bacterial infections ${ }^{\mathrm{a}}$ & 5 \\
\hline Sealpox & 2 \\
\hline Inflammation post necropsy & 4 \\
\hline Contact dermatitis & 4 \\
\hline Non-specific rashes & 10 \\
\hline Respiratory illness & 18 \\
\hline Tuberculosis pneumonia & 2 \\
\hline Bronchitis & 2 \\
\hline Non-specific irritation & 12 \\
\hline Generalized symptoms \& prolonged illness & 14 \\
\hline Brucellosis $^{\mathrm{b}}$ & 2 \\
\hline Leptospirosis $^{a_{1} b}$ & 2 \\
\hline Erysipelothricosis $^{\mathrm{a}}$ & 1 \\
\hline Tuberculosis pneumonia ${ }^{a}$ & 1 \\
\hline Conjunctivitis & 3 \\
\hline $\begin{array}{l}\text { Systemic effects after traumatic injury } \\
\text { (no specific etiology given) }\end{array}$ & 5 \\
\hline
\end{tabular}


tus, or blood and tissue samples. The factors related to time carried the highest risk, with those exposed most frequently having 23 times (95\% CI 5.3-99.3) greater odds of experiencing a traumatic injury and those exposed for the longest duration having 19 times (95\% CI 3.9-87.4) greater odds of experiencing a traumatic injury than workers with less exposure. Having both exposure to enclosures and equipment and a contact duration of $>5$ yr also quadrupled the odds of injury (95\% CI 1.3-10.5) above workers who primarily had contact with marine mammal carcasses and a shorter contact duration. Conversely, having worked with tissue or blood samples combined with $>5 \mathrm{yr}$ of marine mammal experience decreased odds for injury. Interacting with live marine mammals combined with a contact frequency of $>50 \mathrm{~d} \mathrm{yr}^{-1}$ was similarly protective for trauma (Table 2).

\section{Skin conditions}

From the total number of respondents, $113(23 \%)$ reported having a skin rash or reaction during the time they worked with marine mammals; 73 of these $(64 \%)$ reported that their skin rash or reaction occurred after direct contact with a marine mammal, while 36 (32\%) reported that the ailment appeared after a bite from a marine mammal. The odds of workers acquiring a skin rash or reaction were doubled by having marine mammal contact for $>5$ yr $\left(95 \%\right.$ CI 1.2-2.8) or $>50 \mathrm{~d} \mathrm{yr}^{-1}$ (95\% CI 1.1-2.7); by having contact with marine mammal excretions and/or vomitus (95\% CI 1.1-4.3); and by cleaning or repairing enclosures or equipment (95\% CI 1.1-3.1; Table 3).

Illnesses commonly reported by survey participants included seal finger (Mycoplasma spp. or Erysipelothrix rhusiopathiae); viral dermatitis (poxvirus or herpesvirus); bacterial infections (including Clostridium perfringens, Staphylococcus aureus, Mycobacterium marinum, Corynebacter spp., Pseudomonas spp., Vibrio spp., Pseudomona spp.); and non-specific contact dermatitis. The number of respondents that reported seal finger was 55 (11\%); however, no statistically significant risk factors specifically associated with acquiring seal finger were identified.
Table 2. Risk factors for injury of marine mammal workers. Adjusted odds ratios calculated using multivariate logistic regression; reference category for each estimate includes respondents not reporting exposure to the specific risk ED: exposure duration

\begin{tabular}{|lcc|}
\hline Risk factors & $\begin{array}{c}\text { Number at risk } \\
(\mathrm{n}=483)\end{array}$ & $\begin{array}{c}\text { Adjusted odds } \\
\text { ratio }(95 \% \mathrm{CI})\end{array}$ \\
\hline $\mathrm{ED}>5 \mathrm{yr}$ & 297 & $18.5(3.93-87.40)$ \\
$\mathrm{EF}>50 \mathrm{~d} \mathrm{yr}^{-1}$ & 267 & $23.0(5.32-99.28)$ \\
Contact with live marine mammals & 385 & $7.1(2.10-23.901)$ \\
Contact with tissue/blood samples & 407 & $3.0(1.33-6.78)$ \\
Contact with marine mammal & 365 & $3.3(1.72-6.53)$ \\
excretions/vomitus & & \\
Cleaning or repairing enclosure/equipment & 259 & $1.3(0.73-2.28)$ \\
Cleaning or repairing enclosure/equipment & 159 & $3.7(1.33-10.50)$ \\
\& ED $>5$ yr & & \\
Contact with tissue/blood samples \& ED $>5 \mathrm{yr}$ & 266 & $0.1^{\mathrm{a}}(0.22-0.58)$ \\
Contact with live marine mammals \& & 236 & $0.1^{\mathrm{a}}(0.22-0.50)$ \\
EF $>50 \mathrm{~d}$ yr ${ }^{-1}$ & & \\
aprotective & & \\
\hline
\end{tabular}

Table 3. Risk factors for skin rash/reaction in marine mammal workers. Adjusted odds ratios calculated using multivariate logistic regression; reference category for each estimate includes respondents not reporting exposure to the specific risk factor of interest (95\% CI: confidence interval)

\begin{tabular}{|lcc|}
\hline Risk factors & $\begin{array}{c}\text { Number at risk } \\
(\mathrm{n}=483)\end{array}$ & $\begin{array}{c}\text { Adjusted odds } \\
\text { ratio }(95 \% \mathrm{CI})\end{array}$ \\
\hline Exposure duration $>5 \mathrm{yr}$ & 297 & $1.8(1.15-2.79)$ \\
Exposure frequency $>50 \mathrm{~d} \mathrm{yr}^{-1}$ & 267 & $1.7(1.10-2.72)$ \\
Contact with marine mammal excretions/vomitus 365 & $2.2(1.08-4.27)$ \\
Cleaning or repairing enclosures/equipment & 259 & $1.9(1.12-3.14)$ \\
\hline
\end{tabular}

\section{Respiratory illness}

Out of all of respondents, 18\% ( $\mathrm{n}=89)$ reported experiencing respiratory illness during the time they worked with marine mammals. Of these, only $20 \%$ (18) believed their ailment to be the result of marine mammal contact. Seven of these worked in a rehabilitation setting, 8 in research, and 3 in an oceanarium. Increased frequency of contact was associated with a higher risk of respiratory illness, with workers exposed $>50 \mathrm{~d} \mathrm{yr}^{-1}$ being 3 times more likely to have a respiratory illness than workers with less annual exposure (95\% CI 1.9-5.4).

\section{Generalized symptoms and prolonged malaise}

Of all respondents, $6 \%(n=30)$ reported having suffered prolonged malaise while they worked with marine mammals. Of these, 30\% (9) believed their ill- 
ness was due to marine mammal contact. Most of these cases (5 of 9) were never definitively diagnosed despite all 9 workers seeking medical treatment. There were no statistically significant risk factors associated with prolonged malaise.

\section{DISCUSSION}

While the internet has become a useful tool for administering health surveys, it possesses many of the same flaws of paper-based or in-person surveys. Persons who have experienced a significant impact to their health are much more likely to remember it and to recount it in such a survey, while people who have not experienced adverse health are less likely to respond, leading to a possible non-response bias (Kuusi et al. 2004). Therefore, our data may overestimate the actual risk of injury and illness in people who contact marine mammals. On the other hand, $58.6 \%$ of the survey respondents were members of the research community. As a result of their scientific training, these respondents may have been more likely to require evidence of causation rather than assume that their injuries and illnesses were linked with their marine mammal exposure. The potential for overestimation of prevalence of injury and illness might have been countered by responding scientists' conservative linkages of those injuries and illnesses to marine mammal causes. Written comments by respondents provided evidence that many were aware of the health risks associated with their occupational activities and were making informed decisions regarding their work with marine mammals. One respondent commented, 'Considering the hundreds of necropsies and many months of crawling through fur seal rookery muck (splashed in the face many times), I feel I have really suffered very little in spite of the risks to which I was exposed.' It is also feasible that there could have been rare cases of death resulting from marine mammal contact, making the affected individual unavailable for response. Such deaths are undoubtedly extremely rare or coincidental to marine mammal contact and are unlikely to have influenced estimates; however, we were contacted by the spouse of a marine mammal worker whose husband died after a bite from a pinniped reportedly as a result of a severe hypersensitivity reaction (data not included in analyses).

The most common health problems reported by marine mammal workers were traumatic injuries. Over half of participants reported having been injured by a marine mammal. The analysis of risk factors suggests that individuals who worked in marine mammal facilities or research $>5 \mathrm{yr}$ and those exposed to such work $>50 \mathrm{~d} \mathrm{yr}^{-1}$ had the highest risk for injury. It is logical that prolonged and frequent exposure increased risk for injury proportionately with frequency of contact.

Most injuries described were cuts and scrapes, followed in frequency by bites. It appears that individuals who worked with live marine mammals $>50 \mathrm{~d} \mathrm{yr}^{-1}$ acquired the skills to mitigate injury, as these occupational exposures in combination were protective. This finding is interesting but not unexpected, as individuals allowed to handle marine mammals on a regular basis are likely the most highly trained and trusted employees.

Cleaning or repairing enclosures or equipment was not a significant individual risk factor for injury. Yet when combined with prolonged exposure ( $>5 \mathrm{yr}$ ), this duty carried an increased risk, making workers over 3 times more likely to be injured than cleaning or repairing enclosures or equipment alone. The interaction between these 2 factors supports the logical assertion that prolonged exposure to a risk factor may increase workers' odds of injury. In addition, individuals who had years of experience with these cleaning and repairing duties may have become less vigilant about safety precautions.

While the highest risks of traumatic injury were associated with direct exposure to live marine mammals, people who had contact with tissue or blood samples and those who contacted excretions and vomitus did have elevated and nearly equivalent odds of injury. Given the nature of the exposure, it is likely that the techniques used to collect and process biological samples involved needles, knives, and scalpels, placing the workers at risk of cuts and scrapes. In contrast to the findings associated with cleaning or repairing enclosures, experience (>5 yr) in these workers decreased risk, suggesting that marine mammal workers in technically-demanding or highly-trained positions may be more careful or have developed techniques to safely perform their duties and avoid personal harm. It may also be possible that individuals in these technically-demanding positions have advanced into more administrative positions over time, thereby increasing their duration of exposure but decreasing their frequency of contact and risk of injury over the years.

Although it is difficult to generalize among different types of occupational exposure, our findings are consistent with the reported nonfatal cases of workrelated injuries and illnesses that are recorded by employers under the Occupational Safety and Health Administration's Survey of Occupational Injuries and Illnesses. This study found injuries to be the most common health problem reported in USA workers, and skin ailments to be the second most prevalent non-fatal illness (National Institute for Occupational Safety and Health 2000). Nearly one quarter of our respondents reported experiencing a skin rash or reaction. As with 
injury, people with longer and more frequent exposure were at higher risk for skin ailments. These skin reactions were often associated with exposure to excretions/vomitus and cleaning or repairing activities, and may have been in part due to the handling of caustic and harsh cleaning solutions, as most of the skin reactions were described as contact dermatitis or rashes. Rashes were a common written complaint in individuals handling dead marine mammals. Reaction to something on or growing in decomposing whale flesh was repeatedly described. For example, one survey respondent reported that 'the rash was contracted immediately following direct and prolonged contact with deteriorating whale carcasses; the areas affected were those that were in direct contact with the carcasses; other members of the team had same symptoms after the same type of contact with same animals.'

The skin disease commonly referred to as seal finger deserves particular discussion. More than $10 \%$ of participants reported having experienced seal finger, and at least half of those affected sought diagnostics and treatment from a physician. Mycoplasma phocacerebrale was identified as the likely etiologic agent (Baker et al. 1998); however, seal finger was previously described as being caused by Erysipelothrix rhusiopathiae. Cutaneous infections resulting from both of these organisms are clinically similar. The inoculation site is usually extremely painful, swollen, and erythematous with lymphadenitis being common (Thompson et al. 1993, Robson et al. 1998, Hartley \& Pitcher 2002). Unfortunately, the recommended treatments are very different. E. rhusiopathiae is responsive to penicillins, cephalosporins, and erythromycin, while Mycoplasma spp. are usually resistant to the aforementioned antibiotics and responsive to tetracyclines. Improper treatment of infections caused by either of these organisms could result in local and hematogenous spread, leading to tenosynovitis, osteomyelitis, and, in the case of E. rhusiopathiae, endocarditis. This severity was illustrated by one participant who reported suffering a prolonged malaise $>6$ mo with 'life threatening toxemia/ encephalopathy' as a sequela to a 'minor skin cut' acquired while working with a harbor porpoise carcass. E. rhusiopathiae was cultured from the infection, and despite treatment with 3 different antibiotics, amputation of the affected digit 'proved life-saving.'

Prolonged malaise and respiratory illnesses were infrequently reported; therefore, substantial risk factors were not identified. However, considering the seriousness of the diseases suspected or reportedly diagnosed (including tuberculosis, brucellosis, and leptospirosis), educating workers and volunteers about these zoonotic diseases is very important. They may be difficult to diagnose and can be debilitating or lifethreatening for the patient. One participant suffered for more than 6 mo from a tuberculous pneumonia that her physician attributed to her work with dolphins. Unfortunately, the documentation provided in the survey response did not allow for other possible routes of transmission to be examined. Nonetheless, this marine mammal rehabilitation volunteer experienced night sweats, weight loss, chronic fatigue, and anemia; she was treated for 9 mo with isoniazid for the tuberculosis and 'dozens of antibiotics' for secondary bacterial infections. She wrote that she 'had always been an extremely healthy person,' but now is in search of 'continued medical assistance.' Another participant suffered multiple relapses of a respiratory illness (2 to 4 times per year with a 2 to 4 wk duration) during his 3 yr of rendering marine mammal tissues. His illness was characterized by 'non-specific symptoms,' and differential diagnoses included chronic fatigue syndrome, multiple sclerosis, and brucellosis (since $10 \%$ of the tissues with which he worked were positive for Brucella spp.). A specific diagnosis was never confirmed. This researcher was treated with various antibiotics, some of which improved symptoms temporarily, but the illness recurred.

These cases illustrate a common complaint among respondents: their physicians were inadequately informed about the pathogens that could be transmitted from marine mammals. The variability in risk communication from physician to patient appeared to be very high, with some physicians immediately investigating possible marine mammal zoonoses and others dismissing potential transmission altogether. For example, one participant was told by his physician that there were 'no diseases that could be transmitted from whales to humans - so don't worry about it.' When knowledgeable, patients educated their physicians about the pathogens that marine mammals carry. Multiple respondents reported consulting with wildlife and zoo veterinarians in order to provide adequate information to their physicians on follow-up visits. Since this survey was completed, a pinniped researcher contacted us for advice about confirmation of a diagnosis of a chronic illness characterized by severe headaches: the person had been diagnosed as having leptospirosis by a physician, although all laboratory tests were negative. After a veterinarian's suggestion, further tests were performed indicating the person was suffering from brucellosis, and treatment was changed accordingly.

The prevalence of these severe health problems should not be estimated from these survey results since the occurrences were rare and involved a level of selfdiagnosis that may not be completely reliable. However, the accounts of the above participants' illnesses are not unlike case reports of similar illnesses found in the scientific literature in which the suspected organ- 
ism was demonstrated by laboratory testing as being linked to a marine mammal. In 1988, a seal trainer from Western Australia was diagnosed with tuberculosis caused by Mycobacterium bovis. Diagnosis was made after the trainer developed night sweats, weight loss, exercise intolerance, and a dry productive cough. Bacterial isolates from the trainer and the seals with which he worked were identical based on gel electrophoresis (Brew et al. 1999). Similarly in 1999, a laboratory worker handling marine mammal isolates of Brucella suffered from 'continuing headaches, lassitude, and severe sinusitis.' Brucella organisms cultured from blood samples of the researcher were indistinguishable from the marine mammal Brucella isolate (Brew et al. 1999).

People who work with and around marine mammals are at risk for incurring injury and acquiring zoonotic diseases. Individuals working with marine mammals at least $1 \mathrm{~d} \mathrm{wk}^{-1}$ are at the greatest risk of injury. Fulltime workers and committed volunteers should be advised of the associated risks, and should be encouraged to take the proper safety precautions to minimize exposure to zoonotic diseases. Longer and more frequent exposure to marine mammals increases workers' odds of experiencing a skin ailment, and workers in contact with marine mammal carcasses, excretions, and vomitus must be especially diligent in personal hygiene. Although rare, serious sequelae can result from a seemingly minor skin wound or respiratory infection.

Based on these findings, continued adherence to safety guidelines and the use of protective clothing are recommended to decrease the occurrence of adverse health effects in marine mammal caretakers and researchers. Training of workers, students, and volunteers handling marine mammals should include education on disease risks associated with the zoonotic pathogens that both people and animals carry. Facilities housing marine mammals are encouraged to evaluate risks to their staff and volunteers through disease screening and prevention programs. This information and descriptions of commonly and infrequently reported ailments and their treatments are now available to physicians caring for patients who have contact with marine mammals at www.vetmed.ucdavis.edu/whc/mmz.

Acknowledgements. This study was funded by the United States Marine Mammal Commission through research agreement number K005486-01. The authors thank T. J. Ragen and R. H. Mattlin for aiding project initiation and coordinating funding. We gratefully acknowledge the critical review and contributions of M. J. Weise and J. P. Schroeder.

\section{LITERATURE CITED}

Baker AS, Ruoff KL, Madoff S (1998) Isolation of Mycoplasma species from a patient with seal finger. Clin Infect Dis 27:1168-1170
Brew SD, Perrett LL, Stack JA, Macmillan AP, Staunton NJ (1999) Human exposure to Brucella recovered from a sea mammal. Vet Rec 144:483

Buck CD, Schroeder JP (1990) Public health significance of marine mammal diseases. In: Dierauf LA (ed) Handbook of marine mammal medicine: health, disease, and rehabilitation. CRC Press, Boca Raton, FL, p 163-173

Cates MB, Kaufman L, Grabau JH, Pletcher JM, Schroeder JP (1986) Blastomycosis in an Atlantic bottlenose dolphin. J Am Vet Med Assoc 189:1148-1150

Cawthorn MW (1994) Seal finger and mycobacterial infections of man from marine mammals: occurrence, infection and treatment. Conservation Advisory Science Notes No. 102, Department of Conservation, Wellington

Cawthorn MW (1997) Meat consumption from stranded whales and marine mammals in New Zealand: public health and other issues. Conservation Advisory Science Notes No. 164, Department of Conservation, Wellington

Chastel C, Masure O, Balouet G, Laban P, Lucas A (1975) [The student, the cetacean and swine-fever: a minor epidemic after dissection of a globicephale.]. Nouv Presse Med 4:1803-1805 (in French with English abstract)

> Clark C, McIntyre PG, Evans A, McInnes CJ, Lewis-Jones S (2005) Human sealpox resulting from a seal bite: confirmation that sealpox virus is zoonotic. Br J Dermatol 152: 791-793

Cowan DF, House C, House JA (2001) Public health. In: Dierauf LA, Gulland FMD (eds) Handbook of marine mammal medicine, 2nd edn. CRC Press, Boca Raton, FL, p 767-778

Daniel WW (1999) Biostatistics: a foundation for analysis in the health sciences. Wiley, New York

- Eadie PA, Lee TC, Niazi Z, Lawlor D (1990) Seal finger in a wildlife ranger. Ir Med J 83:117-118

> Flowers DJ (1970) Human infection due to Mycobacterium marinum after a dolphin bite. J Clin Pathol 23:475-477

> Geraci JR, Ridgway SH (1991) On disease transmission between cetaceans and humans. Mar Mamm Sci 7: 191-194

> Hartley JW, Pitcher D (2002) Seal finger-tetracycline is first line. J Infect 45:71-75

> Hicks BD, Worthy GAJ (1987) Sealpox in captive grey seals (Halichoerus grypus) and their handlers. J Wildl Dis 23: 1-6

Johnston RG, Fung J (1969) Bacterial flora of wild and captive porpoises: an inquiry into health hazards to man. J Occup Med 11:276-277

Kuusi M, Nuorti JP, Maunula L, Miettinen I, Pesonen H, Von Bonsdorff $\mathrm{CH}$ (2004) Internet use and epidemiologic investigation of gastroenteritis outbreak. Emerg Infect Dis 10:447-450

Markham RB, Polk BF (1979) Seal finger. Rev Infect Dis 1: 567-569

> McLaughlin JB, Sobel J, Lynn T, Funk E, Middaugh J (2004) Botulism Type E outbreak associated with eating a beached whale, Alaska. Emerg Infect Dis 10:1685-1687

> Myers BJ (1970) Nematodes transmitted to man by fish and aquatic mammals. J Wildl Dis 6:266-271

National Institute for Occupational Safety and Health (2000) Worker health chartbook. Department of Health and Human Services, National Institute for Occupational Safety and Health - Publications Dissemination, Cincinnati, OH, p 127-272

National Marine Fisheries Service (1990) Final environmental impact statement on the use of marine mammals in swimwith-the-dolphin programs. National Oceanic and Atmospheric Administration Doc C 55:328. Office of Protected Resources, Silver Spring, MD

Palmer CJ, Schroeder JP, Fujioka RS, Douglas JT (1991) 
Staphylococcus aureus infection in newly captured Pacific bottlenose dolphins (Tursiops truncatus gilli). J Zoo Wildl Med 22:330-338

> Polley L (2005) Navigating parasite webs and parasite flow: emerging and re-emerging parasitic zoonoses of wildlife origin. Int J Parasitol 35:1279-1294

Robson JM, McDougall R, Van Der Valk S, Waite SD, Sullivan JJ (1998) Erysipelothrix rhusiopathiae: an uncommon but ever present zoonosis. Pathology 30:391-394

Rodahl K (1953) Speck finger, a severe finger infection observed in arctic sealers. Western J Surg Ob Gy 61:39-43

Sargent E (1980) Tetracycline for seal finger. JAMA 244:437

Smith AW, Berry ES, Skilling DE, Barlough JE and others (1998) In vitro isolation and characterization of a calicivirus causing a vesicular disease of the hands and feet.
Clin Infect Dis 26:434-439

Streitfeld MM, Chapman CG (1976) Staphylococcus aureus infections of captive dolphins (Tursiops truncatus) and oceanarium personnel. Am J Vet Res 37:303-305

Symmers WS (1983) Possible case of Lobo's disease acquired in Europe from a bottle-nosed dolphin (Tursiops truncatus). Bull Soc Pathol Exot Filiales 76:777-784

Thompson PJ, Cousins DV, Gow BL, Collins DM, Williamson BH, Dagnia HT (1993) Seals, seal trainers, and mycobacterial infection. Am Rev Respir Dis 147:164-167

Tryland M (2000) Zoonoses of arctic marine mammals. Infect Dis Rev 2:55-64

Webster RG, Geraci J, Petursson G, Skirnisson K (1981) Conjunctivitis in human beings caused by influenza A virus of seals. N Engl J Med 304:911 
Appendix 1. Questionnaire on marine mammal pathogens that can infect humans. Supported by the Marine Mammal Commission in conjunction with the National Marine Fisheries Service (NMFS)

\section{All information provided is anonymous and strictly confidential}

1. How long have you worked in direct contact with marine mammals? (Check one)

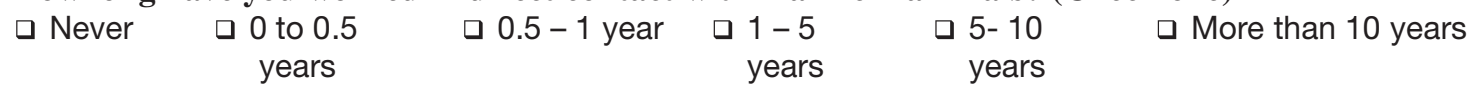

2. On average, how often do (did) you come in contact with marine mammals? (Check one)

$\begin{array}{ccccc}\square & \text { days } \\ \square & 1-25 \text { days } \begin{array}{c}\square \\ 26-50 \\ \text { days }\end{array} & 51-100 \text { days } & \begin{array}{c}101-150 \\ \text { days }\end{array} & \begin{array}{c}\text { More than } 150 \\ \text { days }\end{array}\end{array}$

3. Please indicate situations that describe your work. (Check all that apply)

$\square$ Direct contact with live marine mammals while you are in the water with them

$\square$ Direct contact with live marine mammals while you are out of water

$\square$ Contact with water in which a marine mammal has swum

$\square$ Contact with marine mammal excretions and/or vomitus $\square$ Contact with tissue or blood samples from a marine mammal

Cleaning or repairing enclosures or equipment used in the care of marine mammals

$\square$ Contact with dead marine mammals

4. The majority of your contact with marine mammals is (was) in the area of: (Select one)
$\square$ Research
Rehabilitation
Zoo/aquarium
"Swim with" program

5. Please indicate your training related to marine mammals. (Check all that apply)
Animal restraint/handling
Tissue/blood sampling
Infectious disease prevention

Occupational safety

6. During the time in which you HAVE BEEN in contact with marine mammals, did you ever suffer a traumatic injury caused by the animals?

$\square$ Yes

If Yes, indicate the number of times you had an injury matching the following descriptions (estimates OK).

Located on extremities (i.e. hands, arms)

Deep wound

Located on face

Located centrally (i.e. torso, abdomen)

Superficial scratch or scrape

Deep wound that required stitches

Fractured bones

Cut

Other (describe)

7. During the time in which you were in contact with marine mammals, did you develop a skin rash or reaction?

aYes aNo

If yes, indicate the number of times you had a rash or reaction matching the following descriptions (estimates $\mathrm{OK}$ ).

Reddened

Painful

Itchy

Nodular (raised and hard)

Swollen (raised and soft)
Involved a joint

Oozing

Blister or fluid filled

Located mainly on hands

Located on other places on the body

$$
\text { Specify }
$$

Did the lesions ever appear subsequent to direct contact with a marine mammal? $\quad \square$ Yes $\square$ No

Did these lesions ever appear after a bite from a marine mammal? $\quad \square$ Yes $\square$ No

Were these lesions examined by a medical doctor?

If yes, what were the doctor's diagnoses? 
Appendix 1. (continued)

\section{During the time in which you Have Been in contact with marine mammals, did you} experience any respiratory illnesses?

If yes, approximately how often

Once or twice

$\square$ Once per year $\quad \square 2-4$ times per year

$\square$ Yes

$\square$ No

$\square$ More than once per month

How long was the longest episode?
$\square$ Less than a week
$\square$ 1-2 weeks $\square 2-4$ weeks
1-6 months

$\square$ 5-10 times per year

If yes, please explain.

Were any of these illnesses diagnosed by a medical doctor? $\quad \square$ Yes $\square$ No

What were the doctor's diagnoses?

\section{During the time in which you were in contact with marine mammals, did you ever experience} prolonged malaise?

$\square$ Yes $\square$ No

If yes, how often

$\square$ Once or twice

$\square$ More than once per month

How long was the longest episode?
$\square$ Less than a week
口 1-2 weeks
口 2-4 weeks
a1-6 months

5-10 times per year

months

Do you believe any of these occurrences to be a result of your contact with marine mammals? Yes No If yes, please

explain.

Was this illness diagnosed by a medical doctor?

aYes $\quad$ aNo

What was the doctor's diagnosis?

10. Please describe any additional symptoms from which you suffered during the time you were in contact with marine mammals? (Check all that appply)
$\square$ Fever
$\square$ Nausea or Vomiting
$\square$ Headache
$\square$ Fatigue and/or weakness
$\square$ Yellow skin and eyes
Diarrhea
$\square$ Joint pain
$\square$ Red, runny eyes
$\square$ Ulcers on the eyes

11. Have you ever been diagnosed with complications or disease from any of the following? (Check all that appply)
$\square$ Aeromonas
$\square$ Corynebacterium
$\square$ Mycobacteria tuberculosis
$\square$ Mycoplasma
$\square$ Pseudomonas
$\square$ Streptococcus
$\square$ Poxvirus (Seal \& Dolphin Pox)
$\square$ Herpes virus
Blastomycoses

$\square$ Brucella
$\square$ Erysipelothrix
$\square$ Mycobacteria bovis
$\square$ Pasteurella
$\square$ Salmonella
$\square$ Vibrio
$\square$ Influenza
$\square$ Rabies
$\square$ Candida

\section{Have you ever had sealfinger?}

$\begin{array}{ll}\square & \text { Clostridia } \\ \square & \text { Leptospira } \\ \square & \text { Mycobacteria murium } \\ \square & \text { Proteus } \\ \square & \text { Staphylococcus } \\ \square & \text { Calicivirus (San Miguel Sea Lion Virus) } \\ \square & \text { Adenovirus (Sea Lion Hepatitis) } \\ \square & \text { Rotavirus } \\ \square & \text { Aspergillosis }\end{array}$

\section{$\square$ No}

13. Do you believe any of your described illnesses to be a result of contact with marine mammals?

\section{Yes}

If yes, please

Explain: 
Appendix 1. (continued)

14. Have you ever had a positive tuberculosis test during the time you were in contact with marine mammals? aYes aNo

If Yes, was this by aNot tested skin test or chest $\mathrm{x}$-ray

15. Please indicate your gender:

a Male

a Female

If female, did you ever have a miscarriage during the time you were in contact with marine mammals? $\square$ Yes $\quad \square$ No

16. Do you consider your immune system to be intact?

$\square$ Yes aNo

17. Please list medical treatments for specific problems listed above and their success or failure: 